\title{
Concentrated insulins: the new basal insulins
}

This article was published in the following Dove Press journal:

Therapeutics and Clinical Risk Management

9 March 2016

Number of times this article has been viewed

\author{
Elizabeth M Lamos' \\ Lisa M Younk ${ }^{2}$ \\ Stephen N Davis ${ }^{3}$ \\ 'Division of Endocrinology, Diabetes \\ and Nutrition, ${ }^{2}$ Department of \\ Medicine, University of Maryland \\ School of Medicine, ${ }^{3}$ Department \\ of Medicine, University of Maryland \\ Medical Center, Baltimore, MD, USA
}

Correspondence: Stephen N Davis

University of Maryland Medical Center,

22 South Greene Street, N3W42,

Baltimore, MD 2I 20I, USA

$\mathrm{Tel}+\mathrm{I} 4103282488$

Fax + I 4103288688

Email sdavis@medicine.umaryland.edu
Introduction: Insulin therapy plays a critical role in the treatment of type 1 and type 2 diabetes mellitus. However, there is still a need to find basal insulins with 24-hour coverage and reduced risk of hypoglycemia. Additionally, with increasing obesity and insulin resistance, the ability to provide clinically necessary high doses of insulin at low volume is also needed.

Areas covered: This review highlights the published reports of the pharmacokinetic (PK) and glucodynamic properties of concentrated insulins: Humulin-R U500, insulin degludec U200, and insulin glargine U300, describes the clinical efficacy, risk of hypoglycemic, and metabolic changes observed, and finally, discusses observations about the complexity of introducing a new generation of concentrated insulins to the therapeutic market.

Conclusion: Humulin-R U500 has a similar onset but longer duration of action compared with U100 regular insulin. Insulin glargine U300 has differential PK/pharmacodynamic effects when compared with insulin glargine U100. In noninferiority studies, glycemic control with degludec U200 and glargine U300 is similar to insulin glargine U100 and nocturnal hypoglycemia is reduced. Concentrated formulations appear to behave as separate molecular entities when compared with earlier U100 insulin analog compounds. In the review of available published data, newer concentrated basal insulins may offer an advantage in terms of reduced intraindividual variability as well as reducing the injection burden in individuals requiring high-dose and large volume insulin therapy. Understanding the PK and pharmacodynamic properties of this new generation of insulins is critical to safe dosing, dispensing, and administration.

Keywords: degludec, concentrated insulin, glargine, Humulin-R U500, hypoglycemia, type 2 diabetes, type 1 diabetes

\section{Introduction}

The use of insulin is a mainstay of treatment for all individuals with type 1 diabetes mellitus (T1DM) and for many individuals with type 2 diabetes mellitus (T2DM). In T1DM, basal insulin in combination with rapid-acting mealtime insulin provides a close but imperfect substitute for endogenous physiologic insulin production. T2DM is characterized by insulin resistance and progressive beta-cell dysfunction. Obesity adds to inherent insulin resistance in T2DM and may be an independent cause of insulin resistance in T1DM. As body mass index (BMI) increases, the rate of diabetes increases, reaching $>25 \%$ among morbidly obese individuals $(\mathrm{BMI}>40) .{ }^{1}$ As insulin resistance increases and insulin secretion declines, increasing doses of insulin may be required to maintain even near euglycemia. Insulin may be the desired therapy in individuals with T2DM with critical beta-cell failure with significant glucotoxicity, intolerance to or failure of oral anti-hyperglycemic therapy, or patient preference. Insulin treatment is generally initiated at weight-based doses, and individuals with high insulin resistance can require doses of insulin as high as 2 units $/ \mathrm{kg}$ or greater. As the dose of insulin increases, the volume of insulin injected subcutaneously increases. This can result in unpredictable absorption, increased pain, discomfort, and leakage. 
Table I Available concentrated insulins with basal coverage

\begin{tabular}{llll}
\hline Insulin & Regular & Degludec & Glargine \\
\hline Brand name & Humulin- $\mathrm{R}^{\circledR}$ & Tresiba ${ }^{\circledR}$ & Toujeo \\
Manufacturer & Eli Lily & Novo Nordisk & Sanofi \\
$\begin{array}{l}\text { Concentration (units } / \mathrm{mL}) \\
\text { Vial or pen delivery }\end{array}$ & 500 & 200 & 300 \\
$\begin{array}{l}\text { Total insulin dose capacity } \\
\text { of delivery method }\end{array}$ & Vial & Pen & Pen \\
$\begin{array}{l}\text { Maximum single dose delivery } \\
\text { (units/dose) }\end{array}$ & 10,000 units $/ 20 \mathrm{~mL}$ vial & 600 units $/ 3 \mathrm{~mL}$ pen & $450 \mathrm{units} / \mathrm{l.5} \mathrm{mL}$ pen \\
Estimated cost, wholesale (USD) & & & \\
\hline
\end{tabular}

Notes: ${ }^{a}$ Each one is available with manufacturer coupon and rebate; approximate wholesale price may vary by location. Estimated cost assessed as of December, 20I5; bricing is under revision in Europe. Data from Drugs.com ${ }^{64,66}$ and GoodRx. ${ }^{65}$

Abbreviation: USD, US dollar.

The most commonly prescribed insulins are referred to as "U100" insulin in which 100 units of insulin are suspended or dissolved in $1 \mathrm{~mL}$ of liquid. The U100 basal insulins include neutral protamine Hagedorn (NPH), glargine, degludec, and detemir, as well as short-acting human regular insulin and short-acting insulin analogs (such as lispro, aspart, and glulisine). Only Humulin-R U500 (U-500R) has provided basal insulin in a concentrated formulation.

The newest long-acting basal insulins (such as glargine, detemir, and degludec) were important advancements in basal coverage, with more prolonged and stable pharmacokinetic (PK) and pharmacodynamic (PD) characteristics than NPH insulin. At U100 concentrations, they have afforded improved glycemic control with less risk of hypoglycemia when compared with NPH. ${ }^{2}$ However, true 24-hour durability of detemir is variable among patients. Furthermore, despite PK/PD studies demonstrating 24-hour duration of action of certain doses, it has become apparent that lower doses of glargine and/or detemir do not have a reliable 24 hour duration. As a result, nocturnal hypoglycemia ( 0.00 am to $5.59 \mathrm{am}$ ) can still occur when the basal insulin is increased to improve fasting/overnight hyperglycemia. ${ }^{3}$ This has resulted in a proportion of individuals with T1DM and T2DM taking glargine or detemir twice a day (ie, $62.5 \%$ with detemir vs $32.9 \%$ with glargine U100 in T1DM and $48 \%$ with detemir vs $13 \%$ with glargine U100 in T2DM). ${ }^{4-6}$

Therefore, new insulins were developed to have unique and favorable basal insulin action providing sustained glucose-lowering effect without increasing the risk of hypoglycemia, lower intraindividual variability, and potential flexibility in dosing strategy. Additionally, further refinement was required to concentrate the new basal insulin analogs to overcome severe insulin resistance and address the needs of individuals requiring high injection volume burden.

This review highlights the PK and PD properties of U-500R and the newly available concentrated basal insulin formulations, degludec U200, and glargine U300 (Table 1), provides information on the risk of hypoglycemia and metabolic changes associated with use, and discusses the clinical context and complexity of use in a clinical setting using the experience from U-500R practice.

\section{Body of review \\ Introduction to the compounds}

U-500R insulin has been the only concentrated insulin available for use since the 1950s and delivers 500 units of insulin in $1 \mathrm{~mL}$ of solution. It is approved for use in individuals with T1DM and T2DM and provides mealtime and basal coverage. U-500R prescriptions have increased dramatically in the USA, increasing by $137 \%$ from June 2007 to June $2009^{7}$ and $>70 \%$ in vials prescribed per month from January 2007 to June 2008 (equal to 5,720 vials per month) based on IMS Health, National Audit Database information. ${ }^{8}$

Insulin degludec $\left(\right.$ Tresiba $^{\circledR}$ ) or insulin degludec/insulin aspart $\left(\right.$ Ryzodeg $\left.^{\circledR}\right)$ are novel insulin analogs available at 100 units $/ \mathrm{mL}$ and 200 units $/ \mathrm{mL}$. Insulin glargine U300 $\left(\right.$ Toujeo $^{\circledR}$ ) is a highly concentrated form of the U100 strength insulin glargine at 300 units $/ \mathrm{mL}$.

Additional new concentrated insulin formulations are under preclinical investigation including insulin Fluorolog ${ }^{\circledR}$ at 500 units $/ \mathrm{mL}$, concentrated insulin lispro at 200 units $/ \mathrm{mL}$, both with short-acting properties, and insulin BIOD-531 at 400 units $/ \mathrm{mL}$, which has mixed action properties.

\section{PKs and PDs}

\section{Humulin-R U500}

$\mathrm{U}-500 \mathrm{R}$ is five times more concentrated than $\mathrm{U} 100$ regular insulin (U-100R). U-500R has previously been available as beef and pork regular insulin. However, since the 1990s, recombinant DNA technology has been allowed for the development of the current commercially available human insulin preparation. U-500R is formulated with human insulin 
(of recombinant DNA origin) at $500 \mathrm{units} / \mathrm{mL}$ in a solution of glycerin, metacresol (a preservative), zinc oxide, and water. There is a reduced tendency to form hexamers that allow for faster disassociation and absorption in the circulation compared with longer-acting insulin formulations that form multihexamers.

U-500R peaks around 30 minutes, and insulin action and glucose-lowering effect are prolonged ( $\sim 7$ hours) when studied in healthy and obese individuals and in individuals with T2DM (Table 2). ${ }^{9} 10$ The long duration of action has been attributed to the concentration of the formulation. When compared with U-100R, U-500R insulin has not only a lower maximum (or peak) serum insulin concentration (maximum concentration $\left[C_{\max }\right]$ ) but also a prolonged time to insulin $C_{\max }\left(T_{\max }\right) \cdot{ }^{11}$ A total of 24 healthy obese individuals received 50 -unit or 100-unit doses of U-100R and U-500R using a double-blind crossover design. Under euglycemic clamp conditions, the plasma half-life of insulin was 3.3 hours for U-100R and 4.4 hours for U-500R. The delayed action appeared to be the result of attenuated absorption from the subcutaneous depot and/or reduced clearance. Total glucose exposure (defined by total glucose infusion rate [GIR]) was not different between U-100R and U-500R, but PD parameters reflecting the duration of action were prolonged with U-500R. This supports the use of U-500R without concurrent basal insulin. Time to onset reinforces the dosing of U-500R 30 minutes prior to mealtime.

\section{U- 100 and U-200 insulin degludec}

Insulin degludec is able to form multihexamer chains following the subcutaneous injection. A soluble dihexamer is formed when phenol and zinc are present; however, after injection, phenol disperses and degludec forms multihexamer chains. As zinc is depleted, the individual hexamers disassociate into monomers, at which point degludec is able to be absorbed into the blood. ${ }^{12} \mathrm{~A}$ fatty acid side chain buffers the molecules with albumin so that the plasma levels are very high using the current insulin immunoassays and are impossible to interpret. Although PK/PD parameters can be evaluated for degludec in glucose clamp studies, the actual plasma levels of degludec cannot be compared with other insulin analogs. Insulin degludec provides basal coverage and has been studied at both U100 and U200 concentrations.

Degludec U100 was found to be bioequivalent to degludec U200 in individuals with T1DM. ${ }^{13}$ Mean degludec, 24-hour concentration-time profiles and GIR at steady state, total insulin area under the curve (AUC), and $C_{\max }$ were similar between degludec U100 and degludec U200. The glucose-lowering effects of degludec U100 and U200 were evenly distributed over 24 hours after dosing. The median time to maximum degludec U100 and U200 action was 9 hours, steady state was achieved after 48-72 hours of once-daily dosing, and degludec U200 was detectable for at least 120 hours after last dosing.

In the context of the bioequivalence data, the terminal half-life of degludec U100 was twice when compared with glargine U100 (25.4 hours vs 12.5 hours, respectively). ${ }^{14}$ Total exposure to degludec increased proportionately with increasing dose and was evenly distributed through 24 hours post administration. This is in contrast to glargine exposure, in which $60 \%$ of exposure occurred within the first 12 hours of dosing. Day-to-day glucose variability and within-subject variability have been reported to be lower with degludec U100 than glargine. ${ }^{15}$

PK parameters of degludec U100 studied on individuals with T2DM, not on oral antidiabetic drugs (OADs), were similar to those seen in the abovementioned study ${ }^{14}$ on individuals with T1DM. ${ }^{16}$ In a larger analysis of five Phase I studies with individuals of various ages (including elderly populations) and ethnic backgrounds (including African American and Hispanic) with T1DM or T2DM, steady state was similarly observed at 2-3 days with low variability and

Table 2 Select PK/PD and clinical profiles of Humulin-R U500, degludec U200, and glargine U300

\begin{tabular}{|c|c|c|c|}
\hline PK/PD parameter & Humulin-R U5009-11,33 & Degludec U200 $14,17,35,38,39,53,68$ & Glargine U300 $22,25,42,49,67$ \\
\hline Duration of action & $6-10$ hours & 42 hours & $>30$ hours \\
\hline Half-life & 4 hours & 25 hours & $18-19$ hours \\
\hline Steady state & - & $2-3$ days & 5 days \\
\hline $\mathrm{HbA}_{\mathrm{Ic}}$ reduction from & $-1.6 \%(T 2 D M)$ & $-0.4 \%(\text { TIDM })^{\mathrm{a}}$ & $-0.4 \%(\text { TIDM })^{\mathrm{a}}$ \\
\hline baseline & & $-1.3 \%(\mathrm{~T} 2 \mathrm{DM})^{\mathrm{a}}$ & $-0.8 \%(\mathrm{~T} 2 \mathrm{DM})^{\mathrm{a}}$ \\
\hline \multirow[t]{2}{*}{ Weight gain } & $+4.9 \mathrm{~kg}$ & $+0.2 \mathrm{~kg}(\text { TIDM })^{\mathrm{b}}$ & $-0.6 \mathrm{~kg}(\text { TIDM })^{\mathrm{c}}$ \\
\hline & & $-0.11 \mathrm{~kg}(\mathrm{~T} 2 \mathrm{DM})^{\mathrm{b}}$ & $+0.2 \mathrm{~kg}(\mathrm{~T} 2 \mathrm{DM})^{\mathrm{b}}$ \\
\hline
\end{tabular}

Notes: aNoninferior to glargine UI00; ${ }^{b}$ nonsignificant mean difference between comparator and glargine UI00; 'significant mean difference between comparator and glargine UI00.

Abbreviations: PD, pharmacodynamic; PK, pharmacokinetic; TIDM, type I diabetes; T2DM, type 2 diabetes. 
was independent of the degludec U100 dose. ${ }^{17}$ The glucoselowering effect of degludec U100 was not statistically affected by injection site (thigh, upper arm, or abdominal wall), although slightly reduced in the thigh. ${ }^{18}$

Dose adjustment of insulin degludec U100 in renal impairment (down to an estimated glomerular filtration rate $<30 \mathrm{~mL} / \mathrm{min}$ per $1.73 \mathrm{~m}^{2}$ ), hemodialysis, or liver dysfunction (Child-Pugh grade A-C) is not required. ${ }^{19,20}$ Exposure and clearance of degludec U100 were similar to individuals with normal renal and hepatic function, although intensification of glucose monitoring and individualized dosing for those with renal or hepatic impairment is recommended.

\section{Glargine U-300}

Insulin glargine U300 delivers insulin glargine at a higher concentration from the subcutaneous depot than insulin glargine U100. After subcutaneous injection, the acidic solution is neutralized which leads to the formation of a precipitate within the depot from which glargine U300 is slowly released. Glargine U300 shares the same active metabolites (M1 and M2) as glargine $\mathrm{U} 100 .^{21}$

In a study of glargine U300 compared with glargine U100, individuals with T1DM received a single fixed dose of glargine U300 (0.4 units/kg or 0.6 units $/ \mathrm{kg}$ ) and glargine $\mathrm{U} 100$ (0.4 units $/ \mathrm{kg}$ ) for 8 days in a two-sequence crossover study. ${ }^{22}$ Glargine U300 was detectable at 32 hours post injection with 0.4 units $/ \mathrm{kg}$ dosing compared with 28 hours with glargine U100 dosing. Insulin exposure (using AUC) to glargine U300 was evenly distributed across the study interval with reduced fluctuation at both doses compared with glargine U100. In another study of glargine U300, withinday (diurnal variation) total systemic insulin exposure (using $\mathrm{AUC}_{0-24 \text { hours }}$ after dosing) was low over the entire 24-hour study period. ${ }^{23}$

A total of 24 individuals with T1DM received single doses of glargine U300 (0.4 units/ $\mathrm{kg}, 0.6$ units $/ \mathrm{kg}$, and 0.9 units $/ \mathrm{kg}$ ) and glargine U100 (0.4 unit $/ \mathrm{kg})$ in a four-sequence crossover study. ${ }^{24}$ Euglycemic clamps over 36 hours demonstrated a sustained glucose-lowering effect up to the end of the study (36 hours) with glargine U300 compared with a waning effect beyond 24 hours with glargine U100. GIR was flatter with less individuals experiencing variation with glargine U300 compared with glargine U100. Additionally, Becker et al demonstrated that with 0.4 units $/ \mathrm{kg}$ of glargine U300, the glucose-lowering effect was stable through 30 hours post injection compared with a waning effect after 24 hours of injection with 0.4 units $/ \mathrm{kg}$ of glargine U100. ${ }^{22}$ The low GIR observed toward the end of the clamp study suggests that the effects of concentrating glargine result in a fundamentally distinct PK profile from the U100 concentration.

The studies of glargine U300 in renal or hepatic impairment have not been specifically included in the clinical trial data. The manufacturer recommends considering dose adjustment due to the potential for reduced gluconeogenesis and metabolism. ${ }^{25}$ This is similar to manufacturer recommendations for glargine U100 and supported by small studies with glargine U100. ${ }^{26,27}$

\section{Glycemic control and hypoglycemia Humulin-R U500}

Most of the clinical studies of U-500R are small, retrospective cohort studies. These studies mostly consist of individuals with T2DM and severe insulin resistance.

In a study of 40 obese individuals with poorly controlled T2DM (BMI: $40.5 \mathrm{~kg} / \mathrm{m}^{2} ; \mathrm{HbA}_{1 \mathrm{c}}$ : 9.4\%) previously treated with alternate insulin treatment with or without oral therapy, 1 year of treatment with $\mathrm{U}-500 \mathrm{R}$ resulted in a mean $\mathrm{HbA}_{1 \mathrm{c}}$ reduction of $1.4 \%$ with $38 \%$ of subjects achieving an $\mathrm{HbA}_{1 \mathrm{c}}<7.5 \%$ by 12 months. ${ }^{28}$ However, this was at the expense of an increased total daily dose (TDD; 1.75 units $/ \mathrm{kg} / \mathrm{d}$ to $2.21 \mathrm{units} / \mathrm{kg} / \mathrm{d}$ ) and a mean weight gain of $5.7 \mathrm{~kg}$ over follow-up. This is similar to results from other small observational studies..$^{29,30}$ The durability of glycemic control appears to be maintained for at least $>3$ years of use. ${ }^{29,31}$

U-500R has been studied in individuals using continuous subcutaneous insulin infusion (CSII). In the largest prospective study, 21 obese individuals with poorly controlled T2DM (BMI: $39.4 \mathrm{~kg} / \mathrm{m}^{2} ; \mathrm{HbA}_{1 \mathrm{c}}: 8.6 \%$ ) and severe insulin resistance (mean insulin requirement of 1.7 units $/ \mathrm{kg}$ ) received U-500R via Omnipod delivery. ${ }^{32}$ Prior treatment included intensive insulin management with or without oral therapy. The mean $\mathrm{HbA}_{1 \mathrm{c}}$ declined by $1.2 \%$ and time spent in a blood glucose target range of $70-180 \mathrm{mg} / \mathrm{dL}$ increased by $71 \%$ as assessed by 72 -hour continuous glucose monitoring at weeks 13,26 , and 52 of treatment. The total daily insulin dose increased by 12 units with a mean change in weight of $5.4 \mathrm{~kg}$. Another study administering $\mathrm{U}-500 \mathrm{R}$ via CSII found similar changes in $\mathrm{HbA}_{1 \mathrm{c}}(-1.6 \%)$ and body weight $(3 \mathrm{~kg})$, but with mean total daily insulin decreased by 14 units.

Meta-analysis evaluated the U-500R use in the multidaily injection (MDI) therapy. The mean reduction from baseline in $\mathrm{HbA}_{1 \mathrm{c}}$ was $-1.6 \%$ (range: $-1.3-1.9 \%$ ). ${ }^{33}$ However, similar to the abovementioned information, this is at the expense of a mean weight gain of $4.9 \mathrm{~kg}$ and an increase in TDD of insulin of 52 units. 


\section{Hypoglycemia}

When U-500R was studied in individuals with T2DM, the frequency of self-reported hypoglycemia was increased after 1 year of treatment. ${ }^{28}$ Since the data were self-reported, hypoglycemic symptoms were often reported at blood glucose levels $>70 \mathrm{mg} / \mathrm{dL}$. However, when evaluated by qualityof-life (QoL) assessment, subjects reported fewer symptoms of low sugar, fewer reports of second-party assistance, and fewer self-reported blood sugar values $<60 \mathrm{mg} / \mathrm{dL}$ after the use of U-500 insulin. Self-reported hypoglycemic events declined out to 4 years of treatment (an average of 0.5 episodes/person per week). ${ }^{34}$

In the prospective data, U-500R delivered with CSII to individuals with T2DM demonstrated a small, nonsignificant trend toward time spent at blood glucose levels $<70 \mathrm{mg} / \mathrm{dL}$ (range: $1.4 \%-3.7 \%$, time with hypoglycemia after 1 year; $P=0.15) .{ }^{32}$ When U-500R was studied $>3$ years in individuals with CSII, the overall incidence of severe hypoglycemia was low over the study period, with a mean occurrence of 0.1 episodes/patient per year. ${ }^{31}$

\section{U-200 insulin degludec}

Insulin degludec has been predominantly evaluated in individuals with T1DM and T2DM at the U100 concentration, as a component of basal/bolus therapy or OAD with basal therapy. These studies were designed as noninferiority studies with insulin glargine as the comparator. The primary endpoint was a change in $\mathrm{HbA}_{1 \mathrm{c}}$ from baseline.

Three studies were completed using degludec U100 in individuals with T1DM. ${ }^{35-37}$ In these studies, insulin aspart was administered for the prandial bolus therapy. In general, comparable nonsignificant reductions in $\mathrm{HbA}_{1 \mathrm{c}}$ and fasting plasma glucose (FPG) were observed after 16-52 weeks of treatment with insulin degludec U100 vs insulin glargine.

In 373 individuals with T2DM, the administration of degludec U100 or U200 once daily over 22 weeks demonstrated a similar reduction in $\mathrm{FPG}$ and $\mathrm{HbA}_{1 \mathrm{c}}$ reduction from baseline. ${ }^{38}$ The most significant change in FPG occurred within the first 10 weeks of treatment. Mean daily basal insulin doses were similar between treatment arms. In another study of 26-week duration, degludec U200 once daily in individuals with T2DM inadequately controlled on OAD (mainly metformin but also sulfonylurea [SU], dipeptidyl peptidase-4 [DPP-4] inhibitor, meglitinide, and/or alpha-glucosidase inhibitor) was noninferior to insulin glargine in $\mathrm{HbA}_{\mathrm{lc}}$ reduction $(-1.3 \%$ from baseline, both treatments) ${ }^{39} \mathrm{FPG}$ was significantly lower with insulin degludec compared with insulin glargine $(-67 \mathrm{mg} / \mathrm{dL}$ vs $-61 \mathrm{mg} / \mathrm{dL}$, respectively, $P=0.02$ ).

\section{Hypoglycemia}

When degludec U100 was studied in individuals with T1DM, nocturnal hypoglycemia (0.00 am to $5.59 \mathrm{am})$ was reduced ${ }^{35,36}$ In individuals with T2DM, confirmed hypoglycemia was similar between insulin degludec U200 and insulin glargine and overall hypoglycemia (1.22 episodes/patient per year vs 1.42 episodes/patients per year, respectively) and nocturnal hypoglycemia ( 0.18 episodes/patient per year and 0.28 episodes/patient per year) were similar. ${ }^{39}$

In a large meta-analysis of pooled data from seven trials of insulin degludec (including one study with degludec U200 concentration) vs insulin glargine in individuals with T1DM and T2DM, overall reductions in confirmed hypoglycemia and nocturnal hypoglycemia favored the therapy with insulin degludec. ${ }^{40}$ When analyzed separately, the risk of nocturnal hypoglycemia using degludec was $25 \%$ less in individuals with T1DM and 32\% less in individuals with T2DM. In a meta-analysis of elderly patients (age $\geq 65$ years) with T1DM or T2DM (again including one study with degludec U200 concentration), nocturnal hypoglycemia and severe hypoglycemia were reduced with insulin degludec compared with glargine U100. ${ }^{41}$

\section{Glargine U-300}

Like degludec, glargine U300 has been evaluated in individuals with T1DM and T2DM. A series of studies (EDITION trials) were designed as noninferiority trials vs glargine $\mathrm{U} 100$ with a primary endpoint of $\mathrm{HbA}_{1 \mathrm{c}}$ reduction from baseline. ${ }^{42-49}$ In a 6-month trial, individuals with T1DM and poor glycemic control (mean $\mathrm{HbA}_{1 c}: 8.1 \%$ ) were randomized to insulin glargine $\mathrm{U} 300$ or glargine $\mathrm{U} 100 .{ }^{42} \mathrm{HbA}_{1 \mathrm{c}}$ reduction from baseline was similar ( $-0.4 \%$ vs $0.44 \%$, respectively). Total insulin dose was slightly greater in those receiving glargine U300 $(+0.09 \mathrm{U} / \mathrm{kg})$. In a similarly designed trial in Japanese individuals with T1DM, insulin glargine U300 was noninferior to glargine $\mathrm{U} 100$ in $\mathrm{HbA}_{1 \mathrm{c}}$ reduction from baseline. ${ }^{47}$

There have been three pivotal clinical studies of glargine U300 on individuals with T2DM. In a 6-month trial, individuals with poorly controlled T2DM (mean $\mathrm{HbA}_{1 \mathrm{c}}: 8.2 \%$ ) on basal/bolus insulin $>42$ units/d with or without metformin therapy received either glargine U300 or glargine U100 once daily with bolus insulin titrated to an FPG (4.5-5.6 mmol/L). ${ }^{49}$ Mean $\mathrm{HbA}_{1 \mathrm{c}}$ reduction was similar in both the treatment groups $(-0.8 \%)$. FPG reduction was also similar. TDD of insulin was increased but similar between groups at the end of the study period. In the 6-month extension trial, $\mathrm{HbA}_{1 \mathrm{c}}$ and FPG reduction was similarly durable. ${ }^{43}$ 
Another 6-month trial of individuals with poorly controlled T2DM (mean $\mathrm{HbA}_{1 \mathrm{c}}: 8.2 \%$ ) on basal insulin and select OADs (metformin, DPP-4 inhibitors, thiazolidinedione) received either glargine U300 or glargine U100 once daily titrated to an FPG (4.5-5.6 mmol/L). ${ }^{46}$ Baseline OAD doses were maintained. Again, glargine U300 was similar to glargine $\mathrm{U} 100$ with regard to $\mathrm{HbA}_{1 \mathrm{c}}$ and FPG reduction. Individuals receiving glargine $\mathrm{U} 300$ were more likely to receive a higher basal insulin dose compared with glargine U100. Finally, individuals with T2DM (mean $\mathrm{HbA}_{1 \mathrm{c}}$ : 8.5\%) on OADs alone were randomized to glargine U300 or glargine U100 once daily for 6 months following the discontinuation of SU or glinide therapy. ${ }^{44}$ Again, glargine U300 was noninferior to glargine U100 in achieving glycemic targets $\left(\mathrm{HbA}_{1 \mathrm{c}}\right.$ and FPG reduction). Similar to the previous study, the total dose of glargine U300 was slightly higher than that observed with glargine U100. Bedtime administration of glargine U300 compared with flexible daily dosing at alternate times in individuals with T2DM on MDI or insulin + OAD was studied $>3$ months. The results demonstrated similar glycemic efficacy with both regimens and thus the ability to take $\mathrm{U} 300$ at any time rather than at just bedtime. ${ }^{48}$

\section{Hypoglycemia}

When glargine U300 was studied in individuals with T1DM, nocturnal or any-time hypoglycemia was similar or reduced when compared with glargine U100. ${ }^{42,47}$ From baseline to week 8 of treatment (in 6-month trials), nocturnal hypoglycemia was reduced when compared with glargine U100 (relative risk [RR]: 0.69; 95\% confidence interval [CI]: 0.53-0.91). ${ }^{42}$ Results from the larger trials in individuals with T2DM demonstrated the reduced hypoglycemia (including nocturnal) with a more pronounced reduction during the first 8 weeks of treatment when compared with glargine U100. ${ }^{44,46,49}$ In the T2DM extension trial, any-time hypoglycemia was similar between treatment groups (RR: 0.94; 95\% CI: 0.89-0.99). ${ }^{43}$ However, individuals receiving glargine U300 were less likely to experience nocturnal hypoglycemia (RR: 0.84; 95\% CI: 0.75-0.94). A subsequent meta-analysis confirmed that severe and any-time hypoglycemia was reduced with glargine U300 compared with glargine U100. ${ }^{45}$ T2DM trials were heterogeneous, including individuals with long-duration diabetes on insulin therapy effectively more like a T1DM population, and had a greater reduction in hypoglycemia. Additionally, studies on Japanese individuals demonstrated a similar favorable lowering in episodes of nocturnal and severe hypoglycemia. ${ }^{47,50}$

\section{Metabolic parameters}

Initiation and/or intensification of insulin therapy is associated with weight gain, which is generally attributed to anabolic effects and a decrease in glucosuria. U-500R is associated with a mean weight gain of $4 \mathrm{~kg} .{ }^{33}$ This correlates with an increase in TDD of insulin. Mean weight gain with insulin degludec U200 therapy was nonsignificantly increased by $2 \mathrm{~kg}$ over 22 weeks in individuals with T2DM. ${ }^{38}$ Weight gain was significantly lower in individuals with T1DM who received glargine U300 compared with glargine U100 (difference $-0.6 \mathrm{~kg}, P=0.037) .{ }^{42}$ Weight gain has also been reported to be similar with glargine U300 or glargine U100 $(+1.2 \mathrm{~kg}$ vs $+1.4 \mathrm{~kg}$, respectively) after 12 months of treatment in T2DM.

When compared with baseline, up to 3 years of treatment with U-500R did not affect blood pressure or the number of blood pressure medications prescribed. ${ }^{28,34}$ When compared with insulin glargine, the treatment with insulin degludec did not affect blood pressure or heart rate. ${ }^{39}$ Treatment effects of glargine U300 on blood pressure are not available from the EDITION trials. However, a study was completed in which blood pressure response to escalating doses of glargine U300 was assessed, although the results are not yet available. ${ }^{51}$

Several studies of U-500R on individuals with T2DM showed a reduction or no effect on total cholesterol, triglyceride, and high-density lipoprotein cholesterol. Lowdensity lipoprotein cholesterol remained unchanged. ${ }^{28,29,34,52}$ In Phase III trials, the levels of high-density lipoprotein cholesterol, low-density lipoprotein cholesterol, total cholesterol, and triglycerides values appeared similar between degludec U100 and glargine at 26 weeks and 52 weeks. ${ }^{53}$ No clinical effects of glargine U300 on cholesterol are available. There have been no published long-term cardiovascular studies or studies investigating the risk reduction in diabetic microvascular complications with the use of U-500R, degludec, or glargine U300. One ongoing trial does include DEVOTE (A Trial Comparing Cardiovascular Safety of Insulin Degludec Versus Insulin Glargine in Subjects With Type 2 Diabetes at High Risk of Cardiovascular Events). ${ }^{54}$

\section{Discussion}

The need for a once-a-day insulin that provides peak-less basal coverage, 24-hour coverage duration, and low risk for hypoglycemia at low volume is evident. The PK/PD and clinical data support the safe and efficacious use of U-500R, insulin degludec U200, and glargine U300 in individuals with T1DM and T2DM. The PK/PD parameters of degludec U200 and U300 demonstrate the durability and low PK variability 
supporting consistent insulin exposure, especially important in individuals with T1DM. U-500R adequately replaces MDI U100 insulin administration and significantly lowers $\mathrm{HbA}_{1 \mathrm{c}}$ in highly insulin-resistant individuals. Although most clinical data were presented within the context of noninferiority to insulin glargine U100, degludec U200 and glargine U300 appear to be excellent options for long-term glycemic control while providing lower risk of hypoglycemia. These concentrated basal insulins can be safely administered as once daily, in combination with other OADs or mealtime insulin.

The potential market for which degludec U200 and glargine U300 may play a role is increasing. U-500R was the only concentrated insulin therapy available for decades. It has provided glycemic control for the rare individuals with severe insulin resistance from lipodystrophy, genetic defects in the insulin receptor, and those with insulin receptor antibodies. Additionally, U-500R has provided the treatment for more commonly treated individuals with high insulin needs such as in pregnancy, puberty, glucocorticoid use, and obesity. However, it is even more likely that these new concentrated basal insulins may become the standard of basal therapy for any individual with diabetes who requires insulin replacement therapy as they afford lower volume therapy, predictable and durable glycemic control, and lower risk of hypoglycemia compared with glargine U100 and weight gain compared with U-500R, but the use in clinical practice may be more complex than anticipated (Figure 1).

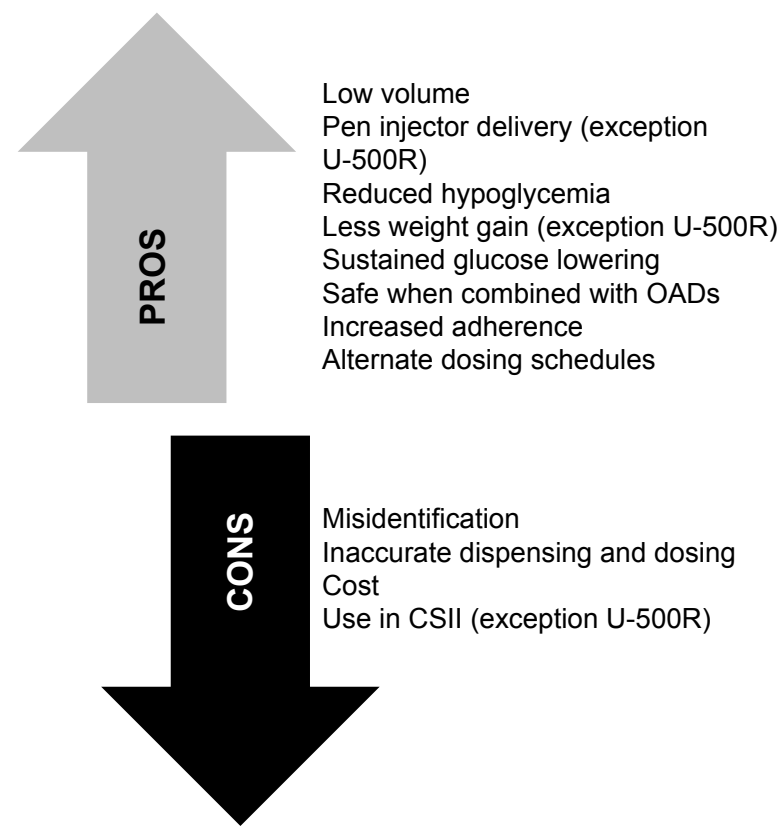

Figure I Pros and cons of concentrated basal insulin therapy.

Abbreviations: CSII, continuous subcutaneous insulin infusion; OADs, oral antidiabetic drugs.
The dosing of U-500R has historically been a challenge. Conversion of U100 to U-500R requires sometimes onerous calculations and often a change in dosing strategy (ie, five injections per day to two to three injections per day). Dosing conversion tables have been provided by the manufacturer of U-500R to eliminate dosage calculation errors. U-500R can be administered using a tuberculous (TB) or U100 insulin syringe, which requires providing both a volumetric and "unitmarking" dosing strategy for the patient and/or pharmacist. Dosing U-500R with a volumetric TB syringe would potentially cause added confusion of dosing, with an increased risk of hypoglycemia. There would also be the expense of larger TB syringe needles with added discomfort, poor pharmacy availability, and poor insurance coverage. The challenges of TB syringe use cannot be overstated. Insulin degludec U200 and glargine U300 can generally be safely converted from current basal therapy with a unit-to-unit conversion.

$\mathrm{U}-500 \mathrm{R}$ is available only in vial. For some individuals who require pen-injector delivery for decreased vision, dexterity, or transport, this is a difficult transition and potentially dangerous. One advantage that degludec U200 and glargine U300 offer is insulin delivery via prefilled pen injectors. These prefilled pens display doses in traditional actual units within the dose unit window. Degludec U200 FlexTouch ${ }^{\circledR}$ pen device allows the administration of doses up to 160 units in a single injection. Toujeo uses a SoloStar ${ }^{\circledR}$ pen device that carries 450 units, 50\% more than the 300-unit glargine U100 pen. Traditional vials containing these new concentrated basal insulins are also needed for use in CSII, where vials are required to fill the insulin reservoir.

Glargine U300 should not be mixed with other forms of insulin due to the low $\mathrm{pH}$ of its diluent. However, degludec can be used in a fixed combination with aspart known as IDegAsp which is currently available in $100 \mathrm{unit} / \mathrm{mL}$ concentration. Both degludec U200 and glargine U300 were well tolerated in combination with OADs in individuals with T2DM. Glargine U300 has been studied as an add-on therapy to metformin, DPP-4 inhibitors, and thiazolidinediones..$^{22,43,44,46,49}$ Degludec was studied as an add-on therapy to metformin, SU, DPP-4 inhibitor, glinide, and/or alpha-glucosidase inhibitor. ${ }^{39,55}$ In addition, degludec has been studied in combination with liraglutide, a glucagon-like peptide-1 agonist, but has not been launched commercially in the USA and would be available at the degludec 100 units/mL concentration. ${ }^{55}$ Glargine U300 is also considered for combination with lixisenatide, another glucagon-like peptide-1 agonist, although the studies of combination therapy have been completed only with glargine U100 at this time. ${ }^{56}$ 
Misidentification and inaccurate dispensing are a potential risk when insulin branding and packaging are similar. U-500R can easily be mistaken for U-100R insulin. The U-500R insulin vial is larger $(20 \mathrm{~mL})$ and thicker with an orange and gray top and striped orange packaging. This is in contrast to U-100R which is a $10 \mathrm{~mL}$ vial with an orange top. In an effort to prevent confusion, patients can be provided identification cards with details regarding U-500R for reference. The largest labeling on both packages is Humulin-R. To the casual observer or unfamiliar pharmacist, these could be mistaken. It has been recommended that U-500R is stored in a different location in the pharmacy to reduce pharmacist confusion. Insulin degludec is available in 100 units $/ \mathrm{mL}$ and 200 units $/ \mathrm{mL}$ and both carry the brand name of Tresiba ${ }^{\circledR}$. Insulin glargine U300 has been marketed as Toujeo $^{\circledR}$ to prevent confusion with glargine U100 (Lantus ${ }^{\circledR}$ ).

Insulin prescribing, dispensing, and administration can be intricate in both the outpatient and inpatient contexts. The new range of available insulins will compound the complexity and potential errors as outpatient insulin regimens are converted to inpatient formulary options or vice versa. The dosing of concentrated insulin in the setting of incurrent illness, hemodynamic instability, diet (ie, NPO status), stress, and/or concurrent medications (ie, glucocorticoids) has not been studied. A consensus has not been reached as to whether or not concentrated insulins should be continued during hospitalization or if these should be switched to U100 options, and there are no current established guidelines for best-practice treatment strategies for inpatient management. Strategies for safely implementing the use of concentrated insulins in inpatient settings could include different storage areas for concentrated insulin or pharmacist pre-drawn insulin. Comprehensive education for the patient as well as the staff who have different education and experience with insulin may be critical to decreasing the risk of medication errors.

As with any new therapy, new basal insulin formulations are costly and may have different coverage with insurance carriers (Table 1). However, in a cohort study comparing individuals on $>150$ units/d of U100 insulin to individuals receiving U-500R, U-500R was associated with a reduced annual pharmacy cost ( $\$ 1,300$ US dollars) compared with U100 insulin (+\$2,600 US dollars). ${ }^{57}$ Perhaps this is due to decreased total cost of U-500R vs the combined cost of basal/ bolus therapy. In economic modeling data, insulin degludec was more cost effective and improved the QoL when compared with insulin glargine U100.58,59

In the same study comparing $>150$ units/d of U100 vs U-500R, adherence was greater in the U-500R group.
Reducing the insulin injection burden from 5-6 per day to 2-3 per day with U-500R may improve adherence. No data are available regarding the adherence to insulin degludec or glargine U300. Insulin degludec and glargine U300 have been tested with alternate dosing schemes (as opposed to fixed morning or evening administration). ${ }^{37,48}$ Degludec U100 was tested using a minimum of 8 hours and a maximum of 40 hours between doses, and glargine U300 was tested every 24 hours \pm 3 hours. This may afford flexibility and improve adherence and perhaps may be more reflective of true dosing among patients. Some individuals will be able to reduce their injection burden from 5 to 4 injections. Additionally, Deg/Asp administration once daily in combination with short-acting insulin at alternate meals may allow for three shots per day. But, none of the new formulations are designed to provide dual basal and daily mealtime coverage that is provided by U-500R.

Ultimately, the efficacy of these new insulins will drive how and when they are incorporated into clinical practice. The major studies of insulin degludec and glargine U300 were designed as noninferiority trials using $\mathrm{HbA}_{1 \mathrm{c}}$ as a primary endpoint. There are no head-to-head long-term $\mathrm{HbA}_{1 \mathrm{c}}$ durability, cardiovascular, or microvascular risk reduction studies.

Another major driver to prescribing new concentrated basal insulins may be reduction in hypoglycemic events. Hypoglycemia and fear of hypoglycemia are the barriers to treatment intensification and adherence. ${ }^{60}$ It is a common fear in children, elderly individuals, those with long-duration diabetes, and those with comorbid conditions such as renal or hepatic diseases. This can be especially compounded in the setting of insulin therapy intensification or insulin add-on therapy to OADs. Additionally, nocturnal hypoglycemia is frequently asymptomatic and is associated with a poor QoL. ${ }^{61,62}$ Insulin detemir and glargine U100 have already proven to be superior to NPH insulin in the reduction in hypoglycemia. ${ }^{2}$ Further, the rates of hypoglycemia appear to be lowered with glargine U300 and degludec. Methods of assessment and reporting of hypoglycemia varied by trial making head-tohead comparison a challenge. For trial inclusion, individuals with recurrent hypoglycemia were excluded making translation to clinical practice in high-risk populations unknown. Nocturnal hypoglycemia was reduced but the majority of hypoglycemic events occurred during daytime, suggesting that the factors that may be most involved in hypoglycemia are the complex interplay between food, exercise/movement, and prandial insulin dosing and timing and not titration of basal insulin to a specified FPG. In addition, previous basal insulin therapy was predicated on once-daily dosing for the majority 
of individuals; however, insulin effects waned before 24 hours which for some individuals would require compensation with short-acting insulin hereby expanding the potential for hypoglycemia. Alternate dosing studies and prolonged duration of action are reassuring that the real-life administration of these new concentrated basal insulins will afford flexibility and prevent hypoglycemia in these scenarios. Confidence in lower risk of hypoglycemia and predictable durability of these new concentrated basal insulins may encourage physicians to intensify the therapy. In the case of U-500R, the risk of hypoglycemia may be intimately tied to the mixed basal/ bolus characteristics and dosing, whereby increasing doses or injections for basal coverage may result in "stacking" resulting in post-mealtime or late-day hypoglycemia.

Glycemic efficacy is often at odds with hypoglycemia, whereby insulin intensification improves glycemic measures but increased hypoglycemia or improvement in hypoglycemia is not reflected in improved glycemic control. Thus, physiologic glycemic efficacy with injected insulin still remains elusive. However, the previous barriers of high dose and large volume insulin and risks of hypoglycemia to therapy intensification may be resolved with these new concentrated basal insulins. This may ultimately lead to improvement in glycemic control by virtue of more freedom in therapy intensification which could translate to decreased microvascular complications and decrease in the inflammatory state of hyperglycemia.

\section{Specific patient profiles suited for treatment with concentrated insulin}

The following fictitious scenarios provide possible examples of specific patient profiles that might benefit from the treatment with concentrated insulin.

\section{Patient profile \#I}

Mr Jones is a 16-year-old male with congenital generalized lipodystrophy. He is $165 \mathrm{~cm}$ and weighs $52 \mathrm{~kg}$ (BMI: $19 \mathrm{~kg} / \mathrm{m}^{2}$ ). His most recent $\mathrm{HbA}_{1 \mathrm{c}}$ is $9.5 \%$ on $2 \mathrm{~g}$ of immediate-release metformin daily, $45 \mathrm{mg}$ of pioglitazone daily, 80 units of glargine daily, and 28 units of humalog with meals ( $\sim 3.1$ units $/ \mathrm{kg})$. Recommendation: consideration of U-500R insulin based on underlying etiology of insulin resistance and TDD of insulin $>2$ units $/ \mathrm{kg}$; might allow reduction from four injections to two to three injections and improved $\mathrm{HbA}_{1 \mathrm{c}}$.

\section{Patient profile \#2}

Ms Casey is a 65 -year-old woman with a 17 -year history of T2DM. She is obese (BMI: $35 \mathrm{~kg} / \mathrm{m}^{2}$ ) and has difficulty with medication adherence. Her most recent $\mathrm{HbA}_{1 \mathrm{c}}$ is $8.1 \%$ on $2 \mathrm{~g}$ of extended-release metformin daily, $100 \mathrm{mg}$ of sitagliptin daily, and 32 units of detemir twice daily. She refuses additional insulin injections. Recommendation: consideration of degludec U200 or glargine U300 once daily to reduce injection burden to once daily, decrease volume of administered insulin, may improve adherence, and may offer flexible administration timing.

\section{Patient profile \#3}

Ms Roberts is a 32-year-old woman with a 20-year history of T1DM. Her diabetes is complicated by mild nonproliferative diabetic retinopathy and the presence of microalbuminuria. She has a history of nocturnal hypoglycemia and intentionally prefers to maintain her blood sugars $>180 \mathrm{mg} / \mathrm{dL}$. Her most recent $\mathrm{HbA}_{1 \mathrm{c}}$ is $8.4 \%$ on 14 units of glargine daily, 1 unit of novolog $-15 \mathrm{~g}$ of carbohydrate with a sensitivity of 1 unit $-45 \mathrm{mg} / \mathrm{dL}>180 \mathrm{mg} / \mathrm{dL}$. Recommendation: consideration of degludec U200 or glargine U300 once daily in place of glargine U100 to improve insulin durability and reduce the risk of hypoglycemia. If this reduces fear of hypoglycemia, titration of her regimen to improve glycemic control may be possible.

\section{Patient profile \#4}

Mr Klein is a 50-year-old male with a recent diagnosis of T2DM. He is obese (BMI: $29 \mathrm{~kg} / \mathrm{m}^{2}$ ) and is hypertensive. His most recent $\mathrm{HbA}_{1 \mathrm{c}}$ is $12 \%$. He reports persistent polyuria and polydipsia despite initiation and titration of metformin to $1,500 \mathrm{mg}$ daily. Recommendation: consideration of degludec U200 or glargine U300 once daily to improve glycemic control with low volume insulin administration and decreased risk for hypoglycemia.

\section{Conclusion}

U-500R appears to be the optimal therapy in individuals with genetic insulin resistance syndromes. It has the benefit of reduced volume, reduced shot burden, and the breadth of clinical data in use in these syndromes. It has also been studied in pregnancy and is a category B therapy. ${ }^{63}$ The benefit of U-500R is that it has a clear indication for individuals using $>200$ units of insulin per day; however, there are many individuals who do not achieve this high dose of total daily insulin but remain burdened by the doses of insulin that they are currently prescribed. Degludec and glargine U300 have no TDD criteria by which individuals are recommended to achieve before switching therapy. The gift of lower volume injection is universal among 
all patients. As discussed earlier, some patients may decrease their injection burden. Additionally, individuals with T1DM and insulin-requiring T2DM in whom lowering the risk of hypoglycemia is a goal degludec and glargine U300 appear to be superior to the standard treatment with glargine U100 in this context.

Ultimately, these new concentrated basal insulins are a step forward from U100 basal insulins in delivering insulin with predictable durability in a low volume. Providers can feel more confident in true 24-hour duration of action, less hypoglycemia, and lower weight gain - the aspects of the current insulin formulation that remain challenges.

As with any new therapy or introduction of insulin to a naïve patient, education remains the mainstay of prevention of adverse events. The intimate knowledge of the differences between each of these concentrated insulins allows the provider to impart specific information to the patient to optimize injection timing, dosing, and administration and reduction in hypoglycemia. By providing this information, the practitioner conveys patient autonomy to be an active participant in their care.

\section{Disclosure}

The authors report no conflicts of interest in this work.

\section{References}

1. Bays HE, Chapman RH, Grandy S; SHIELD Investigators' Group. The relationship of body mass index to diabetes mellitus, hypertension and dyslipidaemia: comparison of data from two national surveys. Int J Clin Pract. 2007;61(5):737-747.

2. Riddle MC, Rosenstock J, Gerich J; Insulin Glargine 4002 Study Investigators. The treat-to-target trial: randomized addition of glargine or human NPH insulin to oral therapy of type 2 diabetic patients. Diabetes Care. 2003;26(11):3080-3086.

3. Porcellati F, Rossetti P, Busciantella NR, et al. Comparison of pharmacokinetics and dynamics of the long-acting insulin analogs glargine and detemir at steady state in type 1 diabetes: a double-blind, randomized, crossover study. Diabetes Care. 2007;30(10):2447-2452.

4. Abali S, Turan S, Atay Z, Guran T, Haliloglu B, Bereket A. Higher insulin detemir doses are required for the similar glycemic control: comparison of insulin detemir and glargine in children with type 1 diabetes mellitus. Pediatr Diabetes. 2015;16(5):361-366.

5. Ashwell SG, Gebbie J, Home PD. Twice-daily compared with once-daily insulin glargine in people with type 1 diabetes using meal-time insulin aspart. Diabet Med. 2006;23(8):879-886.

6. Bryant GA, McDanel DL, Horner KE, Farris KB, Newkirk EN. Evaluation of dosing and clinical outcomes in patients undergoing conversion of insulin glargine to insulin detemir. Pharmacotherapy. 2013;33(1): $56-62$.

7. Segal AR, El Sayed N. Are you ready for more insulin concentrations? J Diabetes Sci Technol. 2015;9(2):331-338.

8. Lane WS, Cochran EK, Jackson JA, et al. High-dose insulin therapy: is it time for U-500 insulin? Endocr Pract. 2009;15(1):71-79.

9. Khan M, Lee Y. The pharmacokinetics and pharmacodynamics of regular U500 insulin in healthy non-obese subjects. Diabetes. 2007; 56(suppl 1):A334-A335.
10. Davidson MB, Navar MD, Echeverry D, Duran P. U-500 regular insulin: clinical experience and pharmacokinetics in obese, severely insulin-resistant type 2 diabetic patients. Diabetes Care. 2010;33(2): 281-283.

11. de la Pena A, Riddle M, Morrow LA, et al. Pharmacokinetics and pharmacodynamics of high-dose human regular U-500 insulin versus human regular U-100 insulin in healthy obese subjects. Diabetes Care. 2011;34(12):2496-2501.

12. Jonassen I, Havelund S, Hoeg-Jensen T, Steensgaard DB, Wahlund PO, Ribel U. Design of the novel protraction mechanism of insulin degludec, an ultra-long-acting basal insulin. Pharm Res. 2012;29(8):2104-2114.

13. Korsatko S, Deller S, Koehler G, et al. A comparison of the steady-state pharmacokinetic and pharmacodynamic profiles of 100 and $200 \mathrm{U} / \mathrm{mL}$ formulations of ultra-long-acting insulin degludec. Clin Drug Investig. 2013;33(7):515-521.

14. Heise T, Hovelmann U, Nosek L, Bottcher S, Granhall C, Haahr H. Insulin degludec has a two-fold longer half-life and a more consistent pharmacokinetic profile compared with insulin glargine. Endocr Abstr. 2012; 28:188.

15. Heise T, Hermanski L, Nosek L, Feldman A, Rasmussen S, Haahr H. Insulin degludec: four times lower pharmacodynamic variability than insulin glargine under steady-state conditions in type 1 diabetes. Diabetes Obes Metab. 2012;14(9):859-864.

16. Heise T, Nosek L, Bottcher SG, Hastrup H, Haahr H. Ultra-long-acting insulin degludec has a flat and stable glucose-lowering effect in type 2 diabetes. Diabetes Obes Metab. 2012;14(10):944-950.

17. Heise T, Korsatko S, Nosek L, et al. Steady state is reached within 2-3 days of once-daily administration of degludec, a basal insulin with an ultralong duration of action. J Diabetes. Epub 2015 Jan 12.

18. Nosek L, Coester HV, Roepstorff C, et al. Glucose-lowering effect of insulin degludec is independent of subcutaneous injection region. Clin Drug Investig. 2014;34(9):673-679.

19. Kiss I, Arold G, Roepstorff C, Bottcher SG, Klim S, Haahr H. Insulin degludec: pharmacokinetics in patients with renal impairment. Clin Pharmacokinet. 2014;53(2):175-183.

20. Kupcova V, Arold G, Roepstorff C, Hojbjerre M, Klim S, Haahr H. Insulin degludec: pharmacokinetic properties in subjects with hepatic impairment. Clin Drug Investig. 2014;34(2):127-133.

21. Steinstraesser A, Schmidt R, Bergmann K, Dahmen R, Becker RH. Investigational new insulin glargine $300 \mathrm{U} / \mathrm{ml}$ has the same metabolism as insulin glargine $100 \mathrm{U} / \mathrm{ml}$. Diabetes Obes Metab. 2014;16(9):873-876.

22. Becker RH, Dahmen R, Bergmann K, Lehmann A, Jax T, Heise T. New insulin glargine 300 Units. $\mathrm{mL}-1$ provides a more even activity profile and prolonged glycemic control at steady state compared with insulin glargine 100 Units. mL-1. Diabetes Care. 2015;38(4):637-643.

23. Becker RH, Nowotny I, Teichert L, Bergmann K, Kapitza C. Low within- and between-day variability in exposure to new insulin glargine 300 U/ml. Diabetes Obes Metab. 2015;17(3):261-267.

24. Tillner J, Bergmann K, Teichert L, Dahmen R, Heise T, Becker R. Euglycemic single dose clamp profile of new insulin glargine formulation in subjects with type 1 diabetes is flat and prolonged; Barcelona 2013.

25. Sanofi-Aventis [webpage on the Internet]. Toujeo [Package Insert]. Available from: http://www.accessdata.fda.gov/drugsatfda_docs/ label/2015/2065381bl.pdf. Accessed November 05, 2015.

26. Pscherer S, Schreyer-Zell G, Gottsmann M. Experience with insulin glargine in patients with end-stage renal disease. Diabetes. 2002; 51(suppl 2):A53.

27. Toyoda M, Kimura M, Yamamoto N, Miyauchi M, Umezono T, Suzuki D. Insulin glargine improves glycemic control and quality of life in type 2 diabetic patients on hemodialysis. J Nephrol. 2012;25(6):989-995.

28. Dailey AM, Williams S, Taneja D, Tannock LR. Clinical efficacy and patient satisfaction with U-500 insulin use. Diabetes Res Clin Pract. 2010;88(3):259-264.

29. Nayyar V, Jarvis J, Lawrence I, et al. Long-term follow up of patients on U-500 insulin: a case series. Pract Diabetes Int. 2010;27(5):194-197. 
30. Boldo A, Comi RJ. Clinical experience with U500 insulin: risks and benefits. Endocr Pract. 2012;18(1):56-61.

31. Lane WS, Weinrib SL, Rappaport JM, Hale CB, Farmer LK, Lane RS. The effect of long-term use of U-500 insulin via continuous subcutaneous infusion on durability of glycemic control and weight in obese, insulin-resistant patients with type 2 diabetes. Endocr Pract. 2013;19(2): 196-201.

32. Lane WS, Weinrib SL, Rappaport JM, Przestrzelski T. A prospective trial of U500 insulin delivered by Omnipod in patients with type 2 diabetes mellitus and severe insulin resistance. Endocr Pract. 2010;16(5): 778-784.

33. Reutrakul S, Wroblewski K, Brown RL. Clinical use of U-500 regular insulin: review and meta-analysis. J Diabetes Sci Technol. 2012;6(2): 412-420.

34. Dailey AM, Gibert JA, Tannock LR. Durability of glycemic control using U-500 insulin. Diabetes Res Clin Pract. 2012;95(3):340-344.

35. Heller S, Buse J, Fisher M, et al. Insulin degludec, an ultra-longacting basal insulin, versus insulin glargine in basal-bolus treatment with mealtime insulin aspart in type 1 diabetes (BEGIN basal-bolus type 1): a phase 3, randomised, open-label, treat-to-target non-inferiority trial. Lancet. 2012;379(9825):1489-1497.

36. Birkeland KI, Home PD, Wendisch U, et al. Insulin degludec in type 1 diabetes: a randomized controlled trial of a new-generation ultra-longacting insulin compared with insulin glargine. Diabetes Care. 2011; 34(3):661-665.

37. Mathieu C, Hollander P, Miranda-Palma B, et al. Efficacy and safety of insulin degludec in a flexible dosing regimen vs insulin glargine in patients with type 1 diabetes (BEGIN: Flex T1): a 26-week randomized, treat-to-target trial with a 26-week extension. J Clin Endocrinol Metab. 2013;98(3):1154-1162.

38. Bode BW, Chaykin LB, Sussman AM, et al. Efficacy and safety of insulin degludec $200 \mathrm{U} / \mathrm{mL}$ and insulin degludec $100 \mathrm{U} / \mathrm{mL}$ in patients with type 2 diabetes (begin: compare). Endocr Pract. 2014;20(8): 785-791.

39. Gough SC, Bhargava A, Jain R, Mersebach H, Rasmussen S, Bergenstal RM. Low-volume insulin degludec 200 units/ml once daily improves glycemic control similarly to insulin glargine with a low risk of hypoglycemia in insulin-naive patients with type 2 diabetes: a 26-week, randomized, controlled, multinational, treat-to-target trial: the BEGIN LOW VOLUME trial. Diabetes Care. 2013;36(9):2536-2542.

40. Ratner RE, Gough SC, Mathieu C, et al. Hypoglycaemia risk with insulin degludec compared with insulin glargine in type 2 and type 1 diabetes: a pre-planned meta-analysis of phase 3 trials. Diabetes Obes Metab. 2013;15(2):175-184.

41. Sorli C, Warren M, Oyer D, Mersebach H, Johansen T, Gough SC. Elderly patients with diabetes experience a lower rate of nocturnal hypoglycaemia with insulin degludec than with insulin glargine: a metaanalysis of phase IIIa trials. Drugs Aging. 2013;30(12):1009-1018.

42. Home P, Bergenstal R, Riddle M, et al. Glycemic control and hypoglycemia with new insulin glargine $300 \mathrm{U} / \mathrm{mL}$ in people with T1DM (EDITION 4). Diabetes. 2014;63(suppl 1A):LB19.

43. Riddle MC, Yki-Jarvinen H, Bolli GB, et al. One-year sustained glycaemic control and less hypoglycaemia with new insulin glargine $300 \mathrm{U} / \mathrm{ml}$ compared with $100 \mathrm{U} / \mathrm{ml}$ in people with type 2 diabetes using basal plus meal-time insulin: the EDITION 1 12-month randomized trial, including 6-month extension. Diabetes Obes Metab. 2015;17(9): 835-842.

44. Bolli GB, Riddle MC, Bergenstal RM, et al. New insulin glargine $300 \mathrm{U} / \mathrm{ml}$ compared with glargine $100 \mathrm{U} / \mathrm{ml}$ in insulin-naive people with type 2 diabetes on oral glucose-lowering drugs: a randomized controlled trial (EDITION 3). Diabetes Obes Metab. 2015;17(4): 386-394.

45. Ritzel R, Roussel R, Bolli GB, et al. Patient-level meta-analysis of the EDITION 1, 2 and 3 studies: glycaemic control and hypoglycaemia with new insulin glargine $300 \mathrm{U} / \mathrm{ml}$ versus glargine $100 \mathrm{U} / \mathrm{ml}$ in people with type 2 diabetes. Diabetes Obes Metab. 2015;17(9):859-867.
46. Yki-Jarvinen $\mathrm{H}$, Bergenstal R, Ziemen $\mathrm{M}$, et al. New insulin glargine 300 units $/ \mathrm{mL}$ versus glargine 100 units $/ \mathrm{mL}$ in people with type 2 diabetes using oral agents and basal insulin: glucose control and hypoglycemia in a 6-month randomized controlled trial (EDITION 2). Diabetes Care. 2014;37(12):3235-3243.

47. Matsuhisa M, Kkoyama M, Cheng X, Shimizu S, Hirose T. New insulin glargine $300 \mathrm{U} / \mathrm{mL}$ : glycemic control and hypoglycemia in Japanese people with T1DM (EDITION JP1). Diabetes. 2014;63(suppl 1A):LB22.

48. Riddle M, Bolli G, Home $P$, et al. New insulin glargine $300 \mathrm{U} / \mathrm{mL}$ : efficacy and safety of adaptable vs fixed dosing intervals in people with T2DM. Can J Diabetes. 2014;38(5):S53.

49. Riddle MC, Bolli GB, Ziemen M, et al. New insulin glargine 300 units $/ \mathrm{mL}$ versus glargine 100 units $/ \mathrm{mL}$ in people with type 2 diabetes using basal and mealtime insulin: glucose control and hypoglycemia in a 6-month randomized controlled trial (EDITION 1). Diabetes Care. 2014;37(10):2755-2762.

50. Terauchi Y, Masayoshi K, Cheng X, Shimizu S, Hirose T. Glycemic control and hypoglycemia in Japanese people with T2DM receiving new insulin glargine $300 \mathrm{U} / \mathrm{mL}$ in combination with OADs (EDITION JP2). Diabetes. 2014;63(suppl 1A):LB24.

51. ClinicalTrials.gov [webpage on the Internet]. Euglycemic Clamp Doseresponse Study Comparing a New Insulin Glargine Formulation with Lantus. Available from: https://clinicaltrials.gov/ct2/show/NCT01195 454?term=NCT01195454\&rank=1. Accessed November 04, 2015.

52. Ziesmer AE, Kelly KC, Guerra PA, George KG, Dunn FL. U500 regular insulin use in insulin-resistant type 2 diabetic veteran patients. Endocr Pract. 2012;18(1):34-38.

53. Novo-Nordisk [webpage on the Internet]. Insulin degludec and insulin degludec/insulin aspart treatment to improve glycemic control in patients with diabetes mellitus [Package Insert]. Available from: http://www.fda. gov/downloads/AdvisoryCommittees/CommitteesMeetingMaterials/ Drugs/EndocrinologicandMetabolicDrugsAdvisoryCommittee/ UCM327017.pdf. Accessed November 05, 2015.

54. ClinicalTrials.gov [webpage on the Internet]. A Trial Comparing Cardiovascular Safety of Insulin Degludec Versus Insulin Glargine in Subjects With Type 2 Diabetes at High Risk of Cardiovascular Events (DEVOTE). Available from: https://clinicaltrials.gov/ct2/show/NC T01959529?term $=$ NCT01959529\&rank=1. Accessed November 05, 2015.

55. Kapitza C, Bode B, Ingwersen SH, Jacobsen LV, Poulsen P. Preserved pharmacokinetic exposure and distinct glycemic effects of insulin degludec and liraglutide in IDegLira, a fixed-ratio combination therapy. J Clin Pharmacol. Epub 2015 May 21.

56. Riddle MC, Forst T, Aronson R, et al. Adding once-daily lixisenatide for type 2 diabetes inadequately controlled with newly initiated and continuously titrated basal insulin glargine: a 24-week, randomized, placebo-controlled study (GetGoal-Duo 1). Diabetes Care. 2013;36(9): 2497-2503.

57. Eby EL, Zagar AJ, Wang P, et al. Healthcare costs and adherence associated with human regular u-500 versus high-dose U-100 insulin in patients with diabetes. Endocr Pract. 2014;20(7):663-670.

58. Ericsson A, Pollock RF, Hunt B, Valentine WJ. Evaluation of the costutility of insulin degludec vs insulin glargine in Sweden. J Med Econ. 2013;16(12):1442-1452.

59. Evans M, Wolden M, Gundgaard J, Chubb B, Christensen T. Cost-effectiveness of insulin degludec compared with insulin glargine for patients with type 2 diabetes treated with basal insulin - from the UK health care cost perspective. Diabetes Obes Metab. 2014;16(4): 366-375.

60. Anderbro T, Amsberg S, Adamson U, et al. Fear of hypoglycaemia in adults with type 1 diabetes. Diabet Med. 2010;27(10):1151-1158.

61. Veneman T, Mitrakou A, Mokan M, Cryer P, Gerich J. Induction of hypoglycemia unawareness by asymptomatic nocturnal hypoglycemia. Diabetes. 1993;42(9):1233-1237.

62. Frier BM. How hypoglycaemia can affect the life of a person with diabetes. Diabetes Metab Res Rev. 2008;24(2):87-92. 
63. Dolberg BK, Lenhard MJ. Successful outcome of pregnancy in a patient with generalized lipoatrophic diabetes mellitus. Endocr Pract. 2000;6(1): 34-36.

64. Drugs.com [webpage on the Internet]. Humulin R (concentrated) Price, Coupons, and Patient Assistance Programs. Available from: http://www.drugs.com/price-guide/humulin-r-concentrated. Accessed December 23, 2015.

65. Tresiba [webpage on the Internet]. Available from: http://www.goodrx. com/tresiba?drug-name=tresiba. Accessed December 23, 2015.

66. Drugs.com [webpage on the Internet]. Toujeo Solostar Prices, Coupons and Patient Assistance Programs. Available from: http://www.drugs. com/price-guide/toujeo-solostar. Accessed December 23, 2015.
67. Sanofi-Aventis [webpage on the Internet]. Toujeo [Package Insert]; EMA Summary of Product Characteristics. Available from: http://www.ema.europa.eu/docs/en_GB/document_library/ EPAR_-_Product_Information/human/000309/WC500047935.pdf. Accessed December 25, 2015.

68. Kurtzhals P, Heise T, Strauss HM, et al. Multi-hexamer formation is the underlying mechanism behind the ultra-long glucose-lowering effect of insulin degludec. Paper presented at: American Diabetes Association (ADA) 71st Scientific Session; June, 2011; San Diego, CA.

\section{Publish your work in this journal}

Therapeutics and Clinical Risk Management is an international, peerreviewed journal of clinical therapeutics and risk management, focusing on concise rapid reporting of clinical studies in all therapeutic areas, outcomes, safety, and programs for the effective, safe, and sustained use of medicines. This journal is indexed on PubMed Central, CAS,
EMBase, Scopus and the Elsevier Bibliographic databases. The manuscript management system is completely online and includes a very quick and fair peer-review system, which is all easy to use. Visit http://www.dovepress.com/testimonials.php to read real quotes from published authors.

Submit your manuscript here: http://www.dovepress.com/therapeutics-and-clinical-risk-management-journal 